\title{
Platelet-derived growth factor can predict survival and acute exacerbation in patients with idiopathic pulmonary fibrosis
}

\author{
Toru Arai, Masaki Hirose, Tomoko Kagawa, Kazuyoshi Hatsuda, Yoshikazu Inoue \\ Clinical Research Center, National Hospital Organization Kinki-Chuo Chest Medical Center, Sakai City, Osaka, Japan \\ Contributions: (I) Conception and design: T Arai, Y Inoue; (II) Administrative support: T Arai; (III) Provision of study materials or patients: M \\ Hirose, T Kagawa, K Hatsuda; (IV) Collection and assembly of data: T Arai, M Hirose, T Kagawa, K Hatsuda; (V) Data analysis and interpretation: \\ T Arai, M Hirose, Y Inoue; (VI) Manuscript writing: All authors; (VII) Final approval of manuscript: All authors. \\ Correspondence to: Toru Arai, MD, PhD. Clinical Research Center, National Hospital Organization Kinki-Chuo Chest Medical Center, 1180 \\ Nagasone-Cho, Kita-Ku, Sakai City, Osaka 591-8555, Japan. Email: toarai1192296@gmail.com.
}

\begin{abstract}
Background: Idiopathic pulmonary fibrosis is a fibrotic disease of unknown aetiology and has a poor prognosis. Some patients experience episodes of rapid deterioration known as acute exacerbations (AEs), which are often fatal. This study aimed to clarify whether serum cytokine levels can predict the outcome of idiopathic pulmonary fibrosis.

Methods: This retrospective study included 69 patients with idiopathic pulmonary fibrosis diagnosed according to the 2018 guideline. AE of idiopathic pulmonary fibrosis was diagnosed using the Japanese Respiratory Society criteria. Serum levels of 27 cytokines were measured using the Bio-Plex method. Cytokine production was estimated per lung volume using the serum cytokine level/percent predicted forced vital capacity (\%FVC) value. The ability of the serum cytokine level and serum cytokine level/\%FVC value to predict the prognosis and $\mathrm{AE}$ was examined in a univariate Cox proportional hazards regression model; significant factors were subjected to multivariate analysis with adjustment for significant clinical parameters, including the modified Medical Research Council score.

Results: The study included 57 men and 12 women (median age, 67 years). The modified Medical Research Council score was $\leq 1$ in 47 patients and $\geq 2$ in 22 . None of the serum cytokine levels measured could predict survival or AE; however, the serum platelet-derived growth factor/\% FVC and interleukin$9 / \% \mathrm{FVC}$ values were significant prognostic factors and the serum platelet-derived growth factor/\% FVC and interleukin-13/\%FVC values were significant predictors of AE. Serum platelet-derived growth factor/\%FVC alone was a significant predictor of the prognosis and $\mathrm{AE}$ after adjustment for clinical parameters.

Conclusions: The prognosis of idiopathic pulmonary fibrosis and AEs of the disease could be predicted by the serum platelet-derived growth factor/\%FVC value.
\end{abstract}

Keywords: Acute exacerbation (AE); idiopathic pulmonary fibrosis; platelet-derived growth factor; prognosis; survival

Submitted Aug 31, 2021. Accepted for publication Jan 11, 2022.

doi: $10.21037 /$ jtd-21-1418

View this article at: https://dx.doi.org/10.21037/jtd-21-1418

\section{Introduction}

Idiopathic pulmonary fibrosis (IPF) is a fibrotic lung disease with an unknown aetiology and a poor prognosis (1-3). Patients with IPF usually experience a slow progressive decline in lung function over time; however, for unknown reasons, some patients experience episodes of rapid deterioration known as acute exacerbations (AEs), which are often fatal (1,4-6). Predictors of the prognosis of IPF reportedly include a decline in the percent predicted forced vital capacity (\%FVC), the percent predicted diffusing capacity of carbon monoxide (\%DLco), the modified Medical Research Council (mMRC) score, and desaturation 
on the 6-minute walk test (1). Some of these parameters have also been identified to predict $\mathrm{AE}$ in patients with IPF $(6,7)$ and mainly reflect the severity of IPF.

Various cytokines have been associated with the inflammation and fibrosis involved in the pathogenesis of IPF (8) and their levels in serum have been found to be different from those in controls (9). However, there has been limited research on serum cytokine levels as prognostic factors in IPF. Inoue et al. reported that serum eotaxin/CC chemokine ligand (CCL)18, interleukin (IL)6 , and IL-8 levels were significant prognostic factors (10). Another study examined cytokine levels in bronchoalveolar lavage (BAL) fluid (BALF) and found that IL-8, monocyte chemoattractant protein (MCP)-1, and vascular endothelial growth factor (VEGF) levels were significantly higher in patients with IPF than in controls (11). However, the ability of serum cytokine levels to predict $\mathrm{AE}$ has not been examined in patients with IPF.

Nintedanib has been found to inhibit signal transduction of receptors for platelet-derived growth factor (PDGF), fibroblast growth factor (FGF), and VEGF (12) and its efficacy in IPF suggests that these cytokines have pathophysiological significance. Moreover, in vitro and in vivo investigations have demonstrated an association between serum levels of these cytokines and pulmonary fibrosis (13-19). However, whether or not serum levels of these cytokines can predict survival in patients with IPF and $\mathrm{AE}$ of the disease has yet to be clarified. Therefore, in this study, we measured the serum levels of cytokines associated with inflammation, fibrosis, and angiogenesis in these patients and investigated their ability to predict survival and $\mathrm{AE}$ of IPF.

We present the following article in accordance with the STROBE reporting checklist (available at https://jtd. amegroups.com/article/view/10.21037/jtd-21-1418/rc).

\section{Methods}

The study had a retrospective design and was approved by the National Hospital Organization Kinki-Chuo Chest Medical Center institutional review board (approval numbers 651 and 365) and performed in accordance with the Declaration of Helsinki (as revised in 2013). All study participants provided written informed consent for inclusion of their data in the study.

\section{Subjects}

Patients were selected for enrolment in this single-centre, retrospective observational study as follows. A search of the National Hospital Organization Kinki-Chuo Chest Medical Center database between 2004 and 2009 identified 94 consecutive patients diagnosed to have IPF according to the 2011 American Thoracic Society/European Respiratory Society/Japanese Respiratory Society/Latin American Thoracic Association (ATS/ERS/JRS/ALAT) IPF guidelines (2). Two patients who had AE at the time of diagnosis of IPF were excluded. Serum samples obtained at the time of diagnosis of IPF were available for 71 of the 92 patients; however, samples for two of these patients had already been used in another study. Therefore, we were able to collect serum samples for 69 patients with a diagnosis of IPF. After reconfirming the diagnosis of IPF in all cases using the 2018 ATS/ERS/JRS/ALAT IPF guideline (3), we measured serum cytokine levels in these patients and in 30 healthy controls.

\section{Diagnosis of AE in IPF}

AE of IPF was diagnosed according to the Japanese Respiratory Society diagnostic criteria as follows: (I) within one month of the chronic course of IPF disease progression, the following three conditions should be satisfied: (i) progressively worsening dyspnoea, (ii) new ground-glass opacities evident on high-resolution computed tomography (CT) scans superimposed on a background reticular or honeycomb pattern, and (iii) a reduction of resting $\mathrm{PaO}_{2}$ by more than 10 Torr $(\mathrm{mmHg})$ compared to previous measurements; and (II) exclusion of obvious causes of acutely impaired respiratory function, such as infection, pneumothorax, cancer, pulmonary embolism, and congestive cardiac failure (20,21). Apparent infections were carefully excluded by measuring antibodies for Mycoplasma pneumoniae and Chlamydia pneumoniae in paired sera, $\beta-\mathrm{D}$ glucan, cytomegalovirus antigen (22) and bacterial cultures of blood and sputum. Congestive heart failure was excluded by echocardiography. Pulmonary embolism was excluded by contrast CT and/or echo-Doppler examination.

\section{Clinical findings at time of diagnosis}

Clinical findings at the time of diagnosis of IPF were 
obtained retrospectively from the medical records and included age, sex, body mass index, smoking status, mMRC score (23) and pulmonary function test results. Pulmonary function tests, including FVC and DLco, were performed using a Chestac 8080 spirometer (Chest, Tokyo, Japan). BAL was performed via a flexible bronchoscope as previously described (24).

\section{Evaluation of serum biomarkers}

Serum Krebs von den Lungen (KL)-6 (25) and surfactant protein (SP)-D (26) levels were measured using commercial enzyme-linked immunosorbent assay kits (KL-6: Eizai, Tokyo, Japan; SP-D: Kyowa Medex, Tokyo, Japan) with respective cut-off levels of $500 \mathrm{U} / \mathrm{mL}$ and $110 \mathrm{ng} / \mathrm{mL}$ (27). Cytokine levels in the serum samples were quantified using the Bio-Plex Suspension Array System with the Bio-Plex Pro Human Cytokine Group Panel (Bio-Rad Laboratories Inc, Hercules, CA, USA) according to the manufacturer's instructions. The cytokines measured included IL- $1 \beta$, IL-1ra, IL-2, IL-4, IL-5, IL-6, IL-7, IL-8, IL-9, IL-10, IL-12 (p70), IL-13, IL-15, IL-17A, CCL11, basic FGF (b-FGF), granulocyte colony-stimulating factor (G-CSF), granulocyte-macrophage colony-stimulating factor (GMCSF), interferon (IFN)- $\gamma$, IFN- $\gamma$ inducible protein 10 (IP10)/CXC chemokine ligand (CXCL)10, MCP-1/CCL2, macrophage inflammatory protein (MIP)-1 $\alpha /$ CCL3, MIP$1 \beta / C C L 4$, PDGF-BB, regulated on activation, normal T-cell expressed and secreted (RANTES)/CCL5, tumor necrosis factor (TNF)- $\alpha$, and VEGF. In each patient, cytokine levels beyond the upper or lower limits were defined to be in the upper range or half of the lower range, respectively.

Assuming that the cytokines associated with pulmonary fibrosis would be produced mainly in the lungs, we decided that it would be more meaningful to measure the level of each cytokine in the lung rather than the serum level. We hypothesized that systemic production of cytokines in patients with a more restrictive abnormality would be reflected by increased local cytokine production in the lung. Systemic production of cytokines was roughly estimated by multiplying the serum level by "body size". In this way, we could compare production of each cytokine according to lung volume using the following formula: serum cytokine level $\times$ body size/FVC, i.e., the serum cytokine level/(FVC/ body size). FVC/body size could be expected to show a positive correlation with $\mathrm{FVC} / \mathrm{pFVC}$, i.e., \% FVC, if the predicted FVC (pFVC) in each case was calculated using body size. Therefore, we estimated local production of each cytokine according to lung volume using the serum cytokine level/\%FVC value.

\section{Statistical analysis}

Continuous variables are presented as the median and interquartile range and categorical variables as the number and percentage. The significance of each clinical parameter and serum cytokine level as a predictor of survival and $\mathrm{AE}$ was evaluated by univariate and multivariate Cox proportional hazards regression analyses with a stepwise selection method.

All statistical calculations were performed using SPSS for Macintosh (version 26; IBM Corp., Armonk, NY, USA). A $\mathrm{P}$ value $<0.05$ was considered statistically significant.

\section{Results}

\section{Patient demographics}

Fifty-seven of the 69 patients with IPF were male and 60 had a smoking history. Median (IQR) age was 67 [61-72] years old. Twenty-one patients experienced AE and 31 died during a median observation period of 1,289 days (Table 1). This study included 30 healthy volunteers, with a median age (IQR) of 56 [54-59], of whom 15 were females and 13 were non-smokers. They were significantly younger $(\mathrm{P}<0.001$, Mann-Whitney $\mathrm{U}$ test $)$ and included significantly more females $(\mathrm{P}=0.001$, Chi-square test $)$ and non-smokers $(\mathrm{P}<0.001$, Chi-square test $)$ than IPF patients.

\section{Clinical parameters predicting a poor prognosis and AE of IPF}

Univariate Cox proportional hazards regression analysis identified lower \%FVC, lower \%DLco, an mMRC score $\geq 2$, higher serum levels of KL-6 and SP-D, and higher percentages of neutrophils in BAL to be significant predictors of a poor prognosis. Multivariate analysis with stepwise selection indicated that higher \% FVC, an mMRC score $\geq 2$, and lower percentages of lymphocytes in BAL were predictors of shorter survival in patients with IPF (Table 2).

Univariate Cox proportional hazards regression analysis revealed lower $\% \mathrm{FVC}$, an $\mathrm{mMRC}$ score $\geq 2$, higher serum levels of KL-6 and SP-D, and higher percentages of neutrophils in BAL to be significant predictors of AE. 
Table 1 Patient demographics

\begin{tabular}{|c|c|}
\hline Parameters & $\begin{array}{l}\text { Frequency (\%) or median } \\
\qquad(\mathrm{IQR})\end{array}$ \\
\hline Gender, male/female & $57 / 12(82.6 / 17.4)$ \\
\hline Age, yrs & 67 [61-72] \\
\hline Smoking. NS/ES or CS & 9/60 (13.0/87.0) \\
\hline Diagnosis of IPF, Clinical/SLB & 35/34 (50.7/49.3) \\
\hline BMI & $24.8(23.1-26.1)$ \\
\hline $\mathrm{mMRC},<2 / \geq 2$ & 47/22 (68.1/3.19) \\
\hline$\% \mathrm{FVC}^{*}, \%$ & $76.5(64.0-89.4)$ \\
\hline$\% D L c o * \star, \%$ & $52.2(37.5-62.3)$ \\
\hline $\mathrm{KL}-6^{\star}, \times 100 \mathrm{U} / \mathrm{mL}$ & $8.35(5.85-11.97)$ \\
\hline $\mathrm{SP}-\mathrm{D}^{\star \star}, \times 10 \mathrm{ng} / \mathrm{mL}$ & $18.4(11.0-30.7)$ \\
\hline Neutrophils in BAL ${ }^{*}, \%$ & $2.3(0.8-5.6)$ \\
\hline Lymphocytes in BAL*, \% & $7.3(3.4-12.4)$ \\
\hline Pirfenidone, yes/no & $10 / 59$ \\
\hline Corticosteroids, yes/no & $31 / 38$ \\
\hline Corticosteroid before $A E$, yes/no & $15 / 54$ \\
\hline $\begin{array}{l}\text { Occurrence of acute exacerbation, } \\
\text { yes/no }\end{array}$ & $21 / 48(30.4 / 69.6)$ \\
\hline Last observation: dead/alive & $31 / 38(44.9 / 55.1)$ \\
\hline Observation period, days & $1,289(578-1,867)$ \\
\hline
\end{tabular}

*, $n=68$; ** $n=67, n=69$ for the other parameters. IPF, idiopathic pulmonary fibrosis; SLB, surgical lung biopsy; BMI, body mass index; mMRC, modified Medical Research Council score for shortness of breathe; FVC, forced vital capacity; DLco, diffusing capacity of carbon monoxide; KL-6, Krebs von den Lungen-6; SP-D, surfactant protein-D.

Multivariate analysis with stepwise selection confirmed a lower \%FVC and an mMRC score $\geq 2$ (Table 3) to be significant predictors of $\mathrm{AE}$.

\section{Serum cytokine levels in patients with IPF}

Serum levels of IL-1ra $(\mathrm{P}<0.001)$, IL-2 $(\mathrm{P}=0.007)$, IL-6 $(\mathrm{P}=0.001), \mathrm{IL}-10(\mathrm{P}=0.001), \mathrm{IL}-12(\mathrm{P}<0.001), \mathrm{G}-\mathrm{CSF}$ $(\mathrm{P}=0.001)$, and $\mathrm{PDGF}(\mathrm{P}<0.001)$ were significantly higher and those of IL-9 $(\mathrm{P}=0.005)$, MIP-1 $\beta(\mathrm{P}<0.001)$, and RANTES $(\mathrm{P}=0.016)$ were significantly lower in patients with IPF than in controls (Table 4).

The significance of the serum levels of each cytokine in terms of the prognosis and prediction of $\mathrm{AE}$ was evaluated by Cox proportional hazards regression analysis. None of the cytokine levels could predict survival (Table 5) or AE (Table 6) in patients with IPF.

No significant correlation was found between the serum level of any cytokine and \%FVC (Table 7). Serum levels of IL-12, G-CSF, GM-CSF, MIP- $1 \alpha$, MIP- $1 \beta$ were significantly associated with percentages of neutrophils in BAL, and serum levels of IL-15, MCP-1, and MIP- $1 \alpha$ had significant correlation with percentages of lymphocytes in BAL (Table 7).

\section{Ability of serum cytokine levels per \%FVC to predict a poor prognosis and $A E$}

We evaluated the ability of serum cytokine levels per \%FVC to predict a poor prognosis and $\mathrm{AE}$ by Cox proportional hazards regression analysis.

Univariate Cox analysis revealed that IL-1ra/\% FVC, IL-7/\%FVC, IL-9/\%FVC, IL-17/\%FVC, eotaxin/\%FVC, $\mathrm{b}-\mathrm{FGF} / \% \mathrm{FVC}$, and $\mathrm{PDGF} / \% \mathrm{FVC}$ were significant predictors of poor survival. IL-9/\%FVC and PDGF/\%FVC were identified to be significant factors in multivariate analysis with stepwise selection (Table 8). After adjustment for significant prognostic clinical factors other than \% FVC (i.e., the $\mathrm{mMRC}$ score and lymphocyte percentages in BAL at the time of diagnosis of IPF), the PDGF/\%FVC value was found to be a significant prognostic factor (Table 8).

The serum IL-7/\%FVC, IL-9/\%FVC, IL-13/\%FVC, IL-17/\% FVC, eotaxin/\% FVC, b-FGF/\% FVC, and $\mathrm{PDGF} / \% \mathrm{FVC}$ values were significant predictors of $\mathrm{AE}$ in IPF by univariate analysis (Table 9). Multivariate analysis with stepwise selection revealed that IL-13/\% FVC and $\mathrm{PDGF} / \% \mathrm{FVC}$ were significant predictors of AE. After adjustment for significant clinical predictors of $\mathrm{AE}$ other than \%FVC (i.e., the mMRC score at the time of diagnosis of IPF), the PDGF/\%FVC value was a significant predictor of AE (Table 9).

\section{Correlation between serum cytokine levels per \%FVC and mMRC score}

Correlation between serum cytokine levels per \%FVC and mMRC score was examined by spearman's rank correlation (Table 10). IL-1 /\%FVC, IL-7/\%FVC, IL-9/\%FVC, IL13/\%FVC, IL15/\%FVC, IL17/\%FVC, eotaxin/\% FVC, b-FGF/\%FVC, IFN $\gamma / \% \mathrm{FVC}$, and $\mathrm{TNF} \alpha / \% \mathrm{FVC}$ was significantly correlated with $\mathrm{mMRC}$ score. In addition, IL4/\%FVC and PDGF/\%FVC tended to be correlated with 
Table 2 Univariate and multivariate Cox proportional hazard regression analysis to evaluated prognostic factors

\begin{tabular}{|c|c|c|c|}
\hline Parameters & $\mathrm{HR}$ & $95 \% \mathrm{Cl}$ & $P$ value \\
\hline Gender, male vs. female & 0.987 & $0.403-2.416$ & 0.978 \\
\hline Age & 1.027 & $0.980-1.076$ & 0.272 \\
\hline Smoking, CS or ES vs. NS & 0.877 & $0.336-2.289$ & 0.789 \\
\hline BMI & 0.939 & $0.839-1.051$ & 0.277 \\
\hline mMRC, $\geq 2$ vs. $<2$ & 4.591 & $2.247-9.380$ & $<0.001$ \\
\hline$\% F^{*}$ & 0.950 & $0.930-0.971$ & $<0.001$ \\
\hline$\% D L c o^{* *}$ & 0.960 & $0.939-0.983$ & 0.001 \\
\hline $\mathrm{KL}-6^{\star}, \times 100 \mathrm{U} / \mathrm{mL}$ & 1.056 & $1.018-1.095$ & 0.004 \\
\hline SP-D*,$\times 10 \mathrm{ng} / \mathrm{mL}$ & 1.020 & $1.005-1.036$ & 0.009 \\
\hline \multicolumn{4}{|c|}{ Multivariate analysis stepwise selection procedure } \\
\hline$\% \mathrm{FVC}$ & 0.955 & $0.930-0.982$ & 0.001 \\
\hline mMRC, $\geq 2$ vs. $<2$ & 2.824 & $1.265-6.305$ & 0.011 \\
\hline Lymphocytes in BAL, \% & 0.927 & $0.866-0.991$ & 0.027 \\
\hline
\end{tabular}

Prognostic significance of each parameter was evaluated by univariate Cox proportional hazard regression analysis. Multivariate analysis with stepwise method was performed using all parameters to clarify prognostic factors. *, $n=68 ;{ }^{* *}, n=67, n=69$ for the other parameters. $\mathrm{HR}$, hazard ratio; $\mathrm{Cl}$, confidence interval; IPF, idiopathic pulmonary fibrosis; BMI, body mass index; mMRC, modified Medical Research Council score for shortness of breathe; \%FVC, percent predicted value of forced vital capacity; \%DLco, percent predicted value of diffusing capacity of carbon monoxide; KL-6, Krebs von den Lungen-6; SP-D, surfactant protein.

mMRC score.

Similarly to \% FVC, mMRC score suggests severity of IPF patients. Predictive role of another parameter "serum cytokine levels/mMRC" for prognosis and AE occurrence was examined by Cox proportional hazard regression analysis with stepwise selection procedure (Table 11). PDGF/mMRC and eotaxin/mMRC was a significant prognostic factor. PDGF/mMRC and IL-9/ $\mathrm{mMRC}$ was a significant predictor for $\mathrm{AE}$ occurrence.

\section{Discussion}

In this study, we measured serum cytokine levels in patients with IPF at the time of diagnosis and assessed their ability to predict the outcome in these patients. Serum cytokine levels were not associated with the \% FVC and could not predict outcome of IPF. However, we identified a new parameter, namely the serum cytokine level/\% FVC value, the results for which suggest that PDGF is an important determinant of both survival and AE in patients with IPF. Similar parameter, the serum cytokine level/mMRC, also suggested importance of PDGF as a predictor of mortality and $\mathrm{AE}$ occurrence.

Other studies have investigated serum cytokine levels as biomarkers of the severity of IPF and its prognosis. Serum IL-8 has been reported to be a significant prognostic factor in IPF (28) and to show a significant negative correlation with \% FVC (29); however, IL-2, IL-4, IL-10, IL-12, and IFN- $\gamma$ did not have no significant correlation with \%FVC (29). De Lauretis et al. reported that the serum IL-6 level can predict progression of IPF and mortality (30). Serum CCL18 was correlated with a change in $\%$ FVC and \% TLC, not with \%FVC. Patients with IPF and a serum CCL18 level $>150 \mathrm{ng} / \mathrm{mL}$ were reported to have significantly poor survival than those with a lower CCL18 level (31). The results of our study that none of the 
Table 3 Univariate and multivariate Cox proportional hazard regression analysis to evaluated predictive factors of occurrence of acute exacerbation in IPF

\begin{tabular}{|c|c|c|c|}
\hline Parameters & $\mathrm{HR}$ & $95 \% \mathrm{Cl}$ & $P$ value \\
\hline \multicolumn{4}{|l|}{ Univariate analysis } \\
\hline Gender, Male vs. Female & 0.987 & $0.328-2.913$ & 0.968 \\
\hline Age & 1.044 & $0.984-1.108$ & 0.156 \\
\hline Smoking, CS or ES vs. NS & 0.654 & $0.219-1.949$ & 0.446 \\
\hline Diagnosis of IPF, Clinical vs. SLB & 1.742 & $0.728-4.168$ & 0.212 \\
\hline BMI & 1.000 & $0.873-1.146$ & 0.999 \\
\hline mMRC, $\geq 2$ vs. $<2$ & 4.367 & $1.819-10.483$ & 0.001 \\
\hline$\% \mathrm{FVC}^{*}$ & 0.953 & $0.930-0.977$ & $<0.001$ \\
\hline$\% D L c 0^{\star \star}$ & 0.973 & $0.947-0.999$ & 0.039 \\
\hline Neutrophils in BAL*, \% & 1.083 & $1.004-1.169$ & 0.040 \\
\hline Lymphocytes in BAL*, \% & 0.994 & $0.934-1.059$ & 0.861 \\
\hline $\mathrm{KL}-6^{\star}, \times 100 \mathrm{U} / \mathrm{mL}$ & 1.063 & $1.021-1.106$ & 0.003 \\
\hline SP-D*, $\times 10 \mathrm{ng} / \mathrm{mL}$ & 1.018 & $1.001-1.035$ & 0.036 \\
\hline \multicolumn{4}{|c|}{ Multivariate analysis with stepwise selection procedure } \\
\hline$\% F V C$ & 0.962 & $0.935-0.989$ & 0.007 \\
\hline mMRC, $\geq 2$ vs. $<2$ & 2.741 & $1.063-7.066$ & 0.037 \\
\hline
\end{tabular}

*, $n=68 ;{ }^{* *}, n=67, n=69$ for the other parameters. Prognostic significance of each parameter was evaluated by univariate Cox proportional hazard regression analysis. Multivariate analysis with stepwise method was performed using all parameters to clarify prognostic factors. $\mathrm{HR}$, hazard ratio; Cl, confidence interval; IPF, idiopathic pulmonary fibrosis; BMI, body mass index; mMRC, modified Medical Research Council score for shortness of breathe; \%FVC, percent predicted value of forced vital capacity; \%DLco, percent predicted value of diffusing capacity of carbon monoxide; KL-6, Krebs von den Lungen-6; SP-D, surfactant protein.

serum cytokine levels were associated with $\% \mathrm{FVC}$ is not inconsistent with previous reports. Serum levels of some cytokines associated with inflammation were correlated with cell populations of BAL in our study. This might be because serum levels of inflammatory cytokines were proportional to local cytokine levels in the lung volume.

An investigation of acute respiratory distress syndrome associated with mould infection suggested that the prognostic significance of cytokine levels in BALF might be better than those in serum in IPF (32). In that study, the prognosis could not be predicted by the serum IL-6 level in patients with mould infection complicated by viral or bacterial infection but could be predicted by IL-6 in BALF. Another IPF study found that the MCP-1 (CCL2) level in BALF was higher in non-survivors than in survivors but that serum CCL2 was not associated with mortality (33). Cytokine levels in BALF reflect intrapulmonary cytokine production; however, BAL is not always easy to perform in patients with IPF. Moreover, cytokine levels in BALF do not necessarily reflect cytokine production per lung volume and BAL is not always obtained from the area of fibrosis. We hypothesized that cytokines associated with fibrosis would be produced mainly in the lung and that cytokine production per lung volume would be the parameter with the best predictive ability. Therefore, we decided to use the serum cytokine level/\% FVC value to estimate the prognostic significance of each cytokine.

In this study, univariate analysis revealed that the IL$1 \mathrm{ra} / \% \mathrm{FVC}, \mathrm{IL}-7 / \% \mathrm{FVC}, \mathrm{IL}-9 / \% \mathrm{FVC}, \mathrm{IL}-17 / \% \mathrm{FVC}$, eotaxin/\%FVC, b-FGF/\%FVC, and PDGF/\%FVC values were significant predictors of poor survival and most of these parameters were significantly correlated with mMRC, suggesting severity of IPF. These results show our new parameters might be useful to evaluate severity and mortality of IPF. Most of these cytokines have been associated with pulmonary fibrosis $(13,15,16,34-37)$, 
Table 4 Serum cytokines of IPF and healthy volunteers*

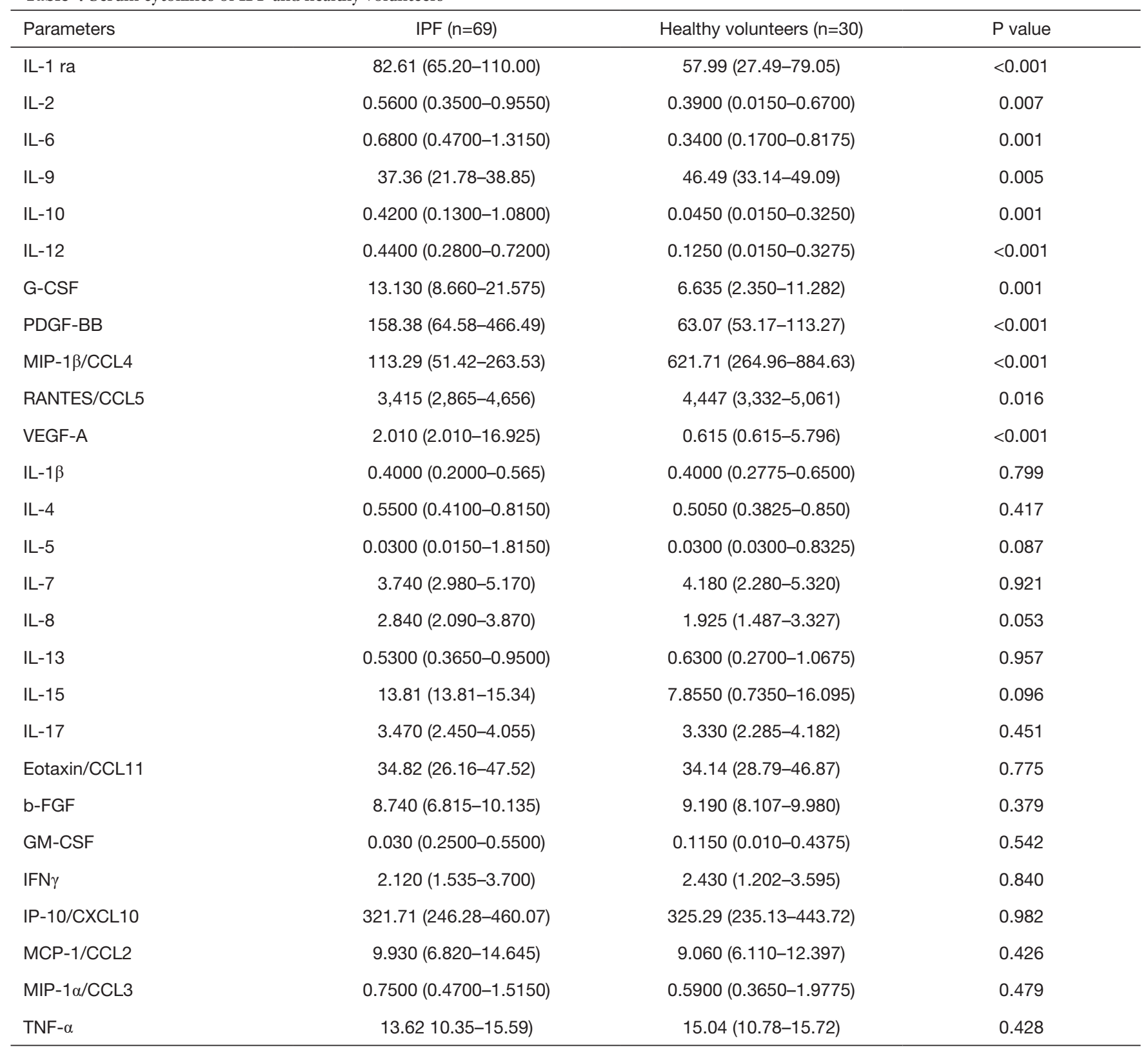

*, serum cytokine levels $(\mathrm{pg} / \mathrm{mL})$ of IPF and healthy volunteers were compared with Mann-Whitney U test. IL, interleukin; CCL, CC chemokine ligand; bFGF, basic fibroblast growth factor; G-CSF; granulocyte colony-stimulating factor; GM-CSF, granulocyte-macrophage colony-stimulating factor; IFN, interferon; IP-10, IFN- $\gamma$ inducible protein; CXCL, CXC chemokine ligand; MCP, monocyte chemotactic protein; MIP, macrophage inflammatory protein; PDGF, platelet-derived growth factor; RANTES, regulated on activation, normal T-cell expressed and secreted; TNF, tumor necrosis factor; VEGF, vascular endothelial growth factor.

probably because the pathophysiology of IPF involves fibrosis more than inflammation. IPF is thought to develop as a result of recurrent injury to alveolar epithelial cells (AECs), which have been associated with endoplasmic reticulum stress and apoptosis of these cells and from aberrant and uncontrolled wound healing thereafter (38). Our multivariate analysis suggested that the PDGF/\%FVC value was the most important predictor of survival in IPF.

PDGF has potent fibrotic activity, activating both proliferation of fibroblasts and collagen synthesis. PDGF 
Table 5 Prognostic significance of serum cytokines determined by univariate Cox proportional hazard regression analysis

\begin{tabular}{|c|c|c|c|}
\hline Parameters ${ }^{*}$ & $H R^{\star *}$ & $95 \% \mathrm{Cl}$ & $P$ value \\
\hline IL-ra & 1.000 & $0.993-1.007$ & 0.983 \\
\hline IL-2 & 0.847 & $0.488-1.470$ & 0.555 \\
\hline IL-4 & 0.465 & $0.146-1.479$ & 0.195 \\
\hline IL-6 & 0.892 & $0.665-1.198$ & 0.447 \\
\hline IL-7 & 0.946 & $0.765-1.170$ & 0.610 \\
\hline IL-8 & 0.988 & $0.964-1.013$ & 0.356 \\
\hline IL-9 & 1.002 & $0.972-1.033$ & 0.908 \\
\hline IL-13 & 1.039 & $0.868-1.234$ & 0.678 \\
\hline IL-15 & 0.994 & $0.974-1.015$ & 0.585 \\
\hline IL-17 & 0.917 & $0.736-1.144$ & 0.443 \\
\hline Eotaxin/CCL11 & 0.987 & $0.957-1.018$ & 0.398 \\
\hline b-FGF & 0.974 & $0.861-1.103$ & 0.682 \\
\hline G-CSF & 0.991 & $0.977-1.005$ & 0.226 \\
\hline GM-CSF & 0.780 & $0.371-1.641$ & 0.513 \\
\hline $\mathrm{IFN} \gamma$ & 0.897 & $0.723-1.114$ & 0.327 \\
\hline RANTES/CCL5 & 1.000 & $1.000-1.000$ & 0.405 \\
\hline TNF- $\alpha$ & 0.966 & $0.916-1.018$ & 0.190 \\
\hline VEGF-A & 0.991 & $0.961-1.023$ & 0.585 \\
\hline
\end{tabular}

${ }^{*}$, cytokine levels were used as $\mathrm{pg} / \mathrm{mL}$; ${ }^{* *}, \mathrm{HR}>1$ means an increase in each continuous parameter indicating high risk of mortality. AE, acute exacerbation; b-FGF, basic fibroblast growth factor; CCL, CC chemokine ligand; Cl, confidence interval; CXCL, CXC chemokine ligand; G-CSF; granulocyte colony-stimulating factor; GM-CSF, granulocyte-macrophage colony-stimulating factor; HR, hazard ratio; HRCT, high-resolution computed tomography; IFN, interferon; IIP, idiopathic interstitial pneumonia; IL, interleukin; IP-10, IFN- $\gamma$ inducible protein; MCP, monocyte chemotactic protein; MIP, macrophage inflammatory protein; PDGF, platelet-derived growth factor; RANTES, regulated on activation, normal T-cell expressed and secreted; TNF, tumor necrosis factor; VEGF, vascular endothelial growth factor. 
Table 6 AE predictive significance of serum cytokines determined by univariate Cox proportional hazard regression analysis

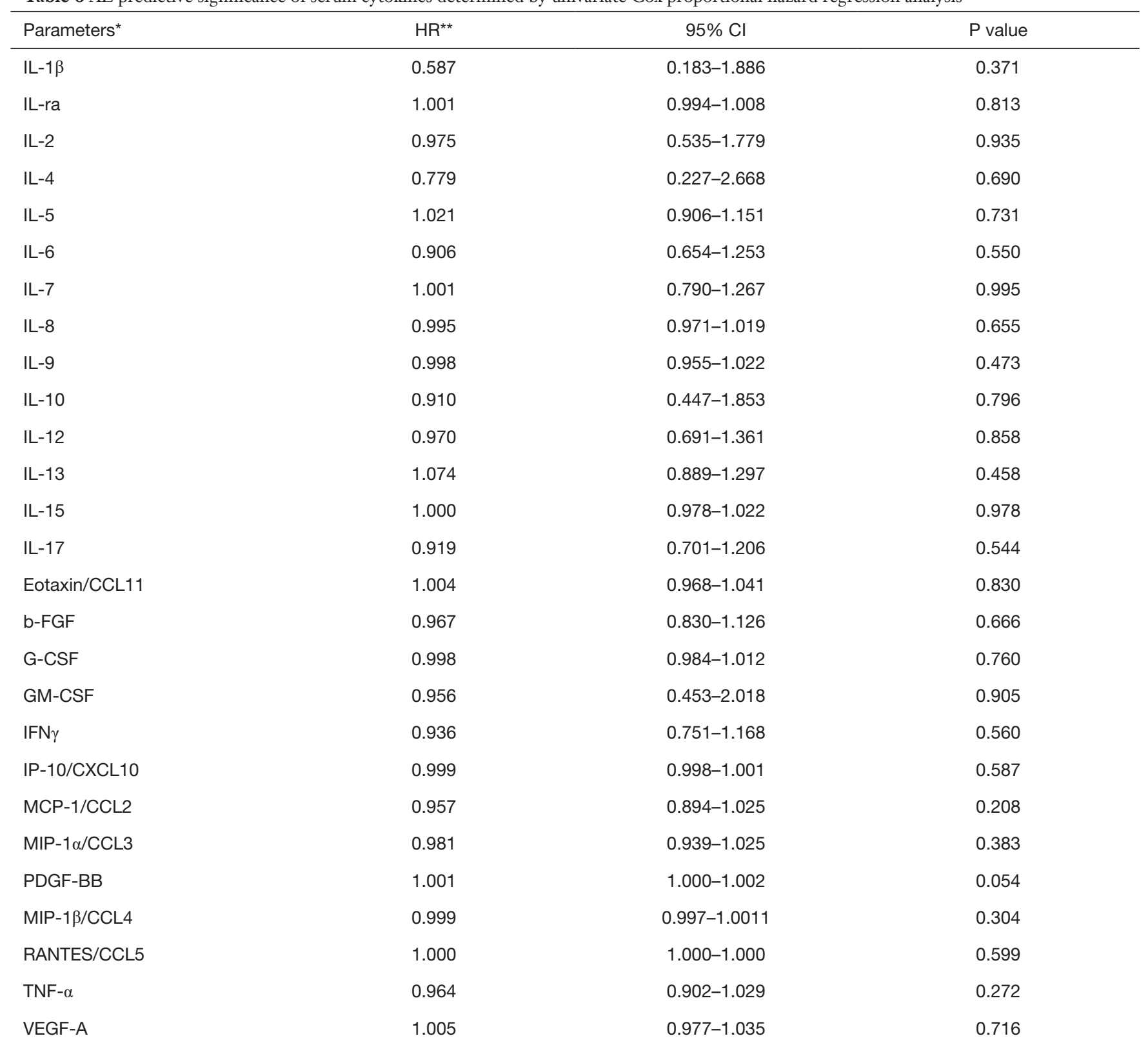

${ }^{*}$, cytokine levels were used as $\mathrm{pg} / \mathrm{mL} ;{ }^{* \star}, \mathrm{HR}>1$ means an increase in each continuous parameter indicating high risk of occurrence of acute exacerbation. AE, acute exacerbation; b-FGF, basic fibroblast growth factor; CCL, CC chemokine ligand; Cl, confidence interval; CXCL, CXC chemokine ligand; G-CSF; granulocyte colony-stimulating factor; GM-CSF, granulocyte-macrophage colony-stimulating factor; HR, hazard ratio; HRCT, high-resolution computed tomography; IFN, interferon; IIP, idiopathic interstitial pneumonia; IL, interleukin; IP-10, IFN- $\gamma$ inducible protein; MCP, monocyte chemotactic protein; MIP, macrophage inflammatory protein; PDGF, platelet-derived growth factor; RANTES, regulated on activation, normal T-cell expressed and secreted; TNF, tumor necrosis factor; VEGF, vascular endothelial growth factor. 
Table 7 Correlation between serum cytokines levels and clinical parameters

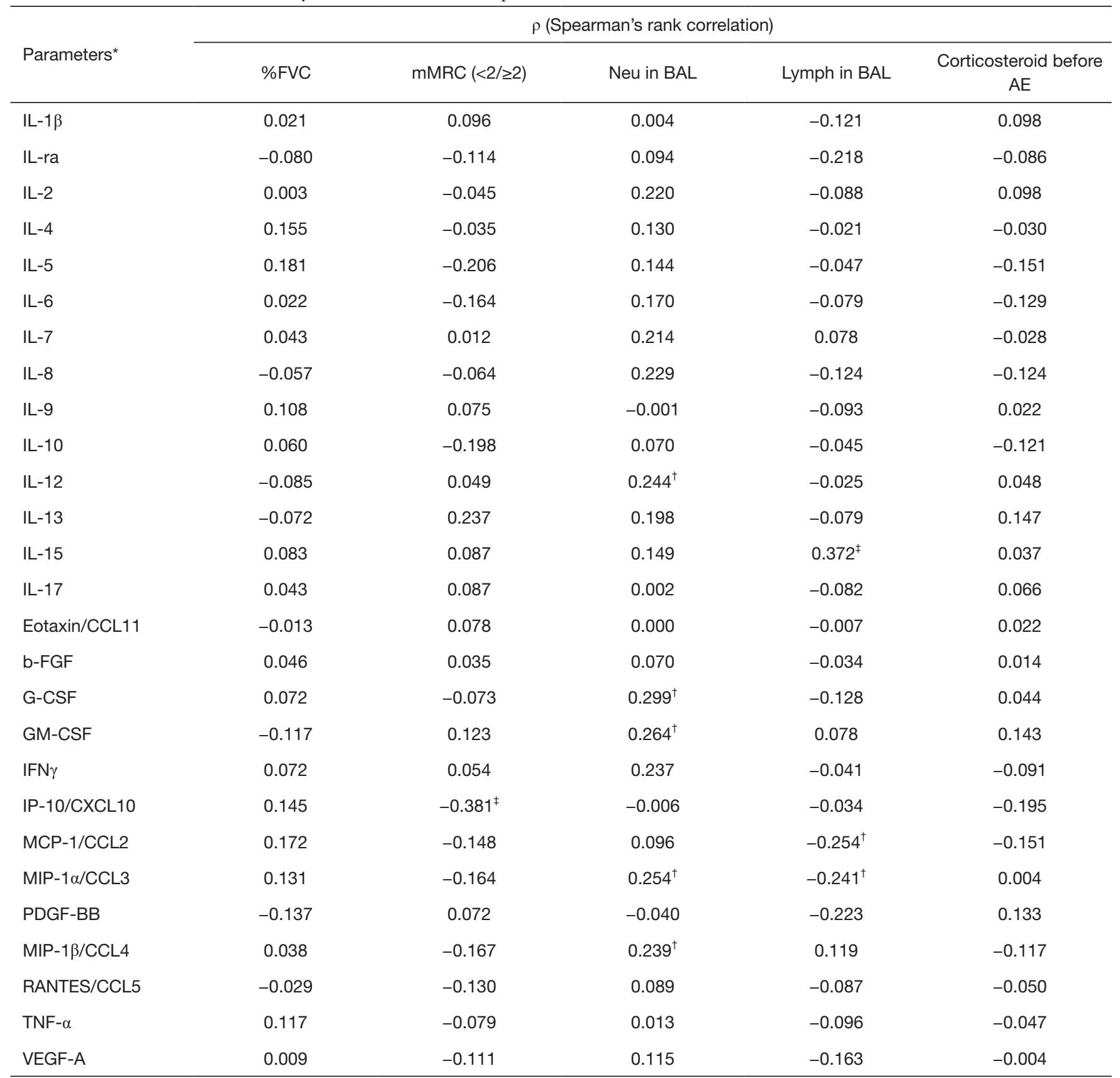

${ }^{\dagger}, \mathrm{P}<0.05 ;{ }^{\ddagger}, \mathrm{P}<0.01$; * , cytokine levels were used as $\mathrm{pg} / \mathrm{mL}$. BAL, bronchoalveolar lavage; b-FGF, basic fibroblast growth factor; CCL, CC chemokine ligand; Cl, confidence interval; CXCL, CXC chemokine ligand; G-CSF; granulocyte colony-stimulating factor; GM-CSF, granulocyte-macrophage colony-stimulating factor; HR, hazard ratio; HRCT, high-resolution computed tomography; IFN, interferon; IIP, idiopathic interstitial pneumonia; IL, interleukin; IP-10, IFN- $\gamma$ inducible protein; Lymph, lymphocytes; MCP, monocyte chemotactic protein; MIP, macrophage inflammatory protein; mMRC, modified Medical Research Council score for shortness of breathe; Neu, neutrophils; \%FVC, percent predicted value of forced vital capacity; PDGF, platelet-derived growth factor; RANTES, regulated on activation, normal T-cell expressed and secreted; TNF, tumor necrosis factor; VEGF, vascular endothelial growth factor. 
Table 8 Prognostic significance of serum cytokines/\%FVC determined by Cox proportional hazard regression analysis

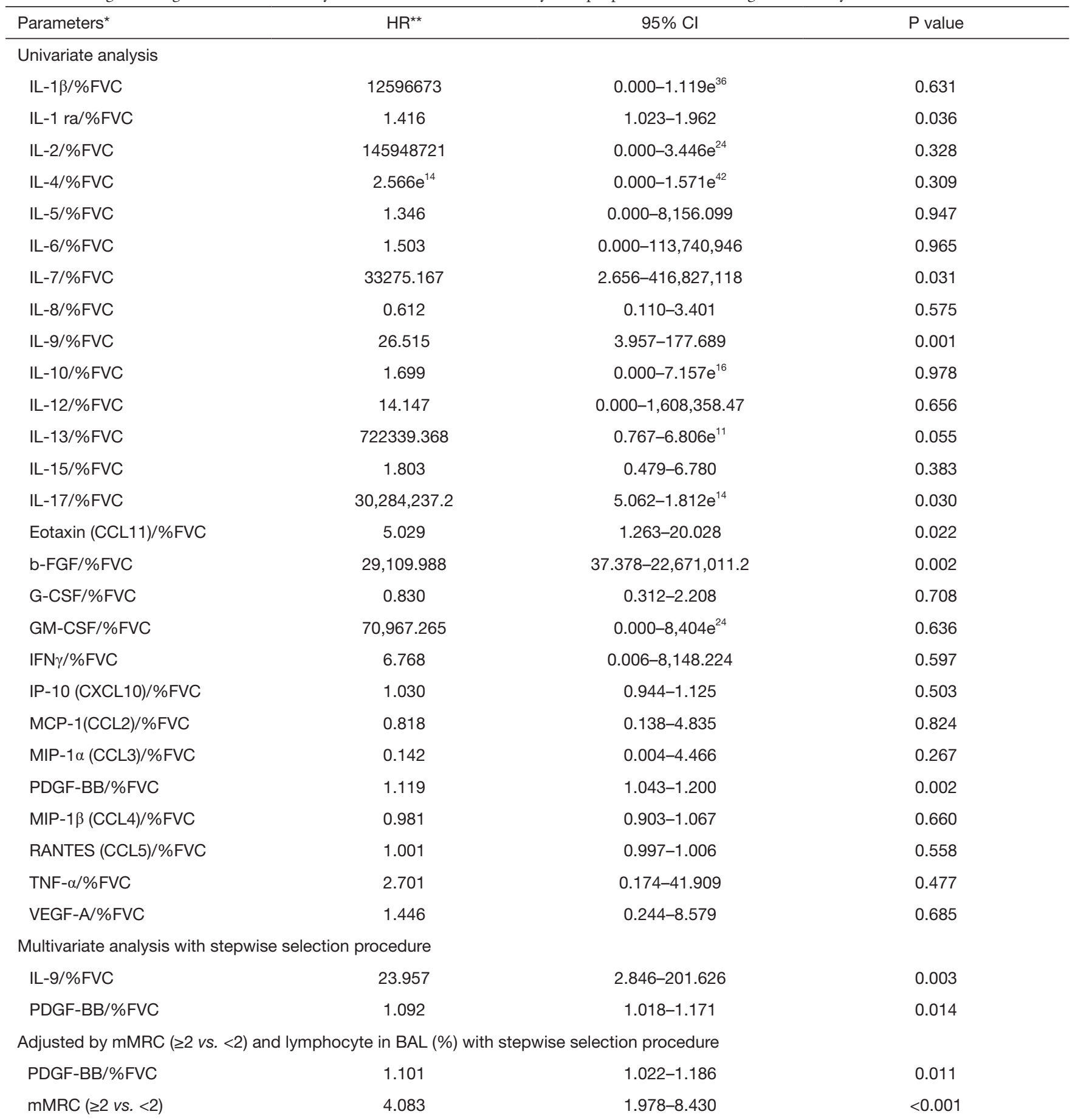

*, cytokine levels were used as $\mathrm{pg} / \mathrm{mL}$; ${ }^{* *}, \mathrm{HR}>1$ means an increase in each continuous parameter indicating high risk of mortality. AE, acute exacerbation; b-FGF, basic fibroblast growth factor; BAL, bronchoalveolar lavage; CCL, CC chemokine ligand; Cl, confidence interval; CXCL, CXC chemokine ligand; G-CSF; granulocyte colony-stimulating factor; GM-CSF, granulocyte-macrophage colonystimulating factor; HR, hazard ratio; HRCT, high-resolution computed tomography; IFN, interferon; IIP, idiopathic interstitial pneumonia; IL, interleukin; IP-10, IFN- $\gamma$ inducible protein; MCP, monocyte chemotactic protein; MIP, macrophage inflammatory protein; mMRC, modified Medical Research Council score for shortness of breathe; \%FVC, percent predicted value of forced vital capacity; PDGF, platelet-derived growth factor; RANTES, regulated on activation, normal T-cell expressed and secreted; TNF, tumor necrosis factor; VEGF, vascular endothelial growth factor. 
Table 9 AE predictive significance of serum cytokines/\%FVC determined by Cox proportional hazard regression analysis

\begin{tabular}{|c|c|c|c|}
\hline Parameters* & $H R^{\star \star}$ & $95 \% \mathrm{Cl}$ & $P$ value \\
\hline IL-1 $\beta / \% F V C$ & $1.257 \mathrm{e}^{9}$ & $0.000-1.037 e^{44}$ & 0.610 \\
\hline IL-ra/\%FVC & 1.373 & $0.984-1.917$ & 0.062 \\
\hline IL-2/\%FVC & $1.915 \mathrm{e}^{13}$ & $0.000-5.734 \mathrm{e}^{31}$ & 0.159 \\
\hline IL-4/\%FVC & $1.101 \mathrm{e}^{27}$ & $0.008-1.556 \mathrm{e}^{56}$ & 0.069 \\
\hline IL-6/\%FVC & 2.722 & $0.000-977,650,401$ & 0.919 \\
\hline IL-7/\%FVC & $98,037.144$ & $4.048-2.374 \mathrm{e} 9$ & 0.026 \\
\hline IL-8/\%FVC & 0.982 & $0.176-5.469$ & 0.983 \\
\hline IL-9/\%FVC & 10.276 & $1.208-87.378$ & 0.033 \\
\hline IL-15/\%FVC & 2.512 & $0.644-9.802$ & 0.185 \\
\hline IL-17/\%FVC & $222,037,044$ & $2.734-1.803 e^{16}$ & 0.039 \\
\hline Eotaxin (CCL11)/\%FVC & 8.611 & $1.972-37.613$ & 0.004 \\
\hline b-FGF/\%FVC & $54,703.892$ & $17.649-169,554,985$ & 0.008 \\
\hline G-CSF/\%FVC & 1.416 & $0.527-3.800$ & 0.490 \\
\hline GM-CSF/\%FVC & $66,901,058.1$ & $0.000-4.228 \mathrm{e}^{24}$ & 0.389 \\
\hline IFN $\gamma / \% F V C$ & 5.156 & $0.005-4,880.085$ & 0.639 \\
\hline IP-10 (CXCL10)/\%FVC & 1.042 & $0.945-1.150$ & 0.408 \\
\hline TNF- $\alpha / \% F V C$ & 3.403 & $0.125-92.146$ & 0.467 \\
\hline VEGF-A/\%FVC & 2.716 & $0.542-13.609$ & 0.224 \\
\hline \multicolumn{4}{|c|}{ Multivariate analysis with stepwise selection procedure } \\
\hline IL-13/\%FVC & $902,694,187$ & $108.785-7.491 e^{15}$ & 0.011 \\
\hline PDGF-BB/\%FVC & 1.147 & $1.063-1.238$ & $<0.001$ \\
\hline \multicolumn{4}{|c|}{ Adjusted by mMRC ( $\geq 2$ vs. $<2$ ) with stepwise procedure } \\
\hline PDGF-BB/\%FVC & 1.133 & $1.045-1.228$ & 0.003 \\
\hline mMRC ( $\geq 2$ vs. $<2)$ & 4.116 & $1.692-10.015$ & 0.002 \\
\hline
\end{tabular}

*, cytokine levels were used as $\mathrm{pg} / \mathrm{mL}$; ${ }^{*}, \mathrm{HR}>1$ means an increase in each continuous parameter indicating high risk of occurrence of acute exacerbation. AE, acute exacerbation; b-FGF, basic fibroblast growth factor; CCL, CC chemokine ligand; $\mathrm{Cl}$, confidence interval; CXCL, CXC chemokine ligand; G-CSF; granulocyte colony-stimulating factor; GM-CSF, granulocyte-macrophage colony-stimulating factor; HR, hazard ratio; HRCT, high-resolution computed tomography; IFN, interferon; IIP, idiopathic interstitial pneumonia; IL, interleukin; IP-10, IFN- $\gamma$ inducible protein; MCP, monocyte chemotactic protein; MIP, macrophage inflammatory protein; mMRC, modified Medical Research Council score for shortness of breathe; PDGF, platelet-derived growth factor; RANTES, regulated on activation, normal T-cell expressed and secreted; TNF, tumor necrosis factor; VEGF, vascular endothelial growth factor. 
Table 10 Correlation between serum cytokine levels/\%FVC and mMRC examined by Spearman's rank correlation

\begin{tabular}{|c|c|c|}
\hline \multirow{2}{*}{ Parameters ${ }^{\star}$} & \multicolumn{2}{|c|}{ Correlation with $\mathrm{mMRC}(<2 / \geq 2)$} \\
\hline & $\rho$ & $P$ value \\
\hline IL-1 $\beta / \% F V C$ & 0.237 & 0.049 \\
\hline IL-ra/\%FVC & 0.194 & 0.111 \\
\hline IL-2/\%FVC & 0.003 & 0.313 \\
\hline IL-4/\%FVC & 0.231 & 0.056 \\
\hline IL-5/\%FVC & 0.003 & 0.980 \\
\hline IL-6/\%FVC & 0.019 & 0.879 \\
\hline IL-7/\%FVC & 0.251 & 0.037 \\
\hline IL-8/\%FVC & 0.108 & 0.378 \\
\hline IL-9/\%FVC & 0.443 & 0.000 \\
\hline IL-10/\%FVC & -0.109 & 0.371 \\
\hline IL-12/\%FVC & 0.194 & 0.111 \\
\hline IL-13/\%FVC & 0.329 & 0.006 \\
\hline IL-15/\%FVC & 0.333 & 0.005 \\
\hline IL-17/\%FVC & 0.356 & 0.003 \\
\hline Eotaxin (CCL11)/\%FVC & 0.365 & 0.002 \\
\hline b-FGF/\%FVC & 0.392 & 0.001 \\
\hline G-CSF/\%FVC & 0.081 & 0.507 \\
\hline GM-CSF/\%FVC & 0.208 & 0.087 \\
\hline IFN $\gamma / \%$ FVC & 0.245 & 0.042 \\
\hline IP-10 (CXCL10)/\%FVC & -0.005 & 0.970 \\
\hline MCP-1(CCL2)/\%FVC & 0.117 & 0.338 \\
\hline MIP-1 $\alpha$ (CCL3)/\%FVC & -0.006 & 0.959 \\
\hline PDGF-BB/\%FVC & 0.205 & 0.092 \\
\hline MIP-1 $\beta$ (CCL4)/\%FVC & 0.002 & 0.990 \\
\hline RANTES (CCL5)/\%FVC & 0.166 & 0.174 \\
\hline TNF- $\alpha / \%$ FVC & 0.278 & 0.021 \\
\hline VEGF-A/\%FVC & 0.044 & 0.721 \\
\hline
\end{tabular}

*, cytokine levels were used as $\mathrm{pg} / \mathrm{mL}$. b-FGF, basic fibroblast growth factor; CCL, CC chemokine ligand; CXCL, CXC chemokine ligand; G-CSF; granulocyte colony-stimulating factor; GM-CSF, granulocyte-macrophage colony-stimulating factor; HR, hazard ratio; IFN, interferon; IL, interleukin; IP-10, IFN- $\gamma$ inducible protein; MCP, monocyte chemotactic protein; MIP, macrophage inflammatory protein; mMRC, modified Medical Research Council score for shortness of breathe; PDGF, platelet-derived growth factor; RANTES, regulated on activation, normal T-cell expressed and secreted; TNF, tumor necrosis factor; VEGF, vascular endothelial growth factor. functions as a strong chemoattractant for fibrocytes (19), which are associated with pulmonary fibrosis. In vivo introduction of the PDGF gene in a rodent model produced histologic findings similar to those in IPF (18). Bleomycin-induced pulmonary fibrosis was inhibited in mice by introduction of the soluble PDGF receptor gene (39) and by imatinib (19) which inhibits PDGF signalling. Furthermore, PDGF mRNA was detected in AECs and alveolar macrophages in patients with IPF $(40,41)$, and production of PDGF by alveolar macrophages from patients with IPF was four times higher than that by those from control donors (42). The results of these studies suggested that serum PDGF is a potentially useful biomarker of the prognosis of IPF; however, clinical significance of serum PDGF levels to predict survival and AE occurrence was not confirmed.

Other studies have found the serum PDGF level to be significantly higher in patients with IPF than in controls $(43,44)$; however, unlike in the present study, its prognostic value was not examined. Zhu et al. measured PDGF mRNA in biopsy specimens from patients with IPF as an indicator of intrapulmonary production of PDGF and found no survival difference according to the PDGF mRNA expression level (45), possibly because of their small sample size and the patchy distribution of fibrotic lesions in IPF (1-3). Hence, expression of PDGF in the biopsy specimens might not have reflected typical intrapulmonary PDGF expression. In this study, we found that a higher serum PDGF/\%FVC value suggested worse survival in patients with IPF. This finding is consistent with the inhibitory effect of nintedanib on PDGF receptor signal transduction (46).

The pathophysiology of AE in IPF involves acute progression of chronic epithelial damage, which may be triggered by infection, aspiration, and mechanical stretch, and its occurrence is thought to depend on the degree of chronic epithelial damage (4). PDGF produced by alveolar macrophages and hyperplastic AECs is thought to be one of the key molecules in pulmonary fibrosis (40-42). Increased production of PDGF in the lung could reflect the degree of chronic lung injury, meaning that the PDGF/\%FVC value can predict both $\mathrm{AE}$ and survival in patients with IPF.

This study has several limitations. First, it had a singlecentre design and included a limited number of cases. Second, serum samples could not be obtained from all 92 consecutive patients with IPF identified during the study period. We could collect serum samples from only 69 IPF patients. Third, age, gender and smoking history of healthy 
Table 11 Predictive role of serum cytokines $/ \mathrm{mMRC}^{\dagger}$ for prognosis and AE occurrence was examined by Cox proportional hazard regression analysis

\begin{tabular}{|c|c|c|c|}
\hline Parameters* & $\mathrm{HR}^{\star *}$ & $95 \% \mathrm{Cl}$ & $P$ value \\
\hline Eotaxin $(\mathrm{CCL} 11) / \mathrm{mMRC}$ & 0.918 & $0.881-0.957$ & $<0.001$ \\
\hline PDGF/mMRC & 1.002 & $1.001-1.004$ & 0.002 \\
\hline \multicolumn{4}{|c|}{ Adjusted by \%FVC with stepwise procedure } \\
\hline PDGF/mMRC & 1.002 & $1.001-1.004$ & 0.016 \\
\hline$\% F V C$ & 0.955 & $0.930-0.981$ & 0.001 \\
\hline \multicolumn{4}{|l|}{ AE occurrence } \\
\hline IL-9/mMRC & 0.880 & $0.813-0.953$ & 0.002 \\
\hline IL-9/mMRC & 0.904 & $0.835-0.980$ & 0.014 \\
\hline $\mathrm{PDGF} / \mathrm{mMRC}$ & 1.003 & $1.001-1.006$ & 0.013 \\
\hline$\% \mathrm{FVC}$ & 0.961 & $0.933-0.991$ & 0.012 \\
\hline
\end{tabular}

${ }^{*}$, cytokine levels were used as $\mathrm{pg} / \mathrm{mL} ;{ }^{* *}, \mathrm{HR}>1$ means an increase in each continuous parameter indicating high risk of mortality or occurrence of acute exacerbation; ${ }^{\dagger}$, the $\mathrm{mMRC}$ scores were used in the calculation as the denominator, mMRC scores from 0 to 4 were converted to from 1 to $5 . \mathrm{AE}$, acute exacerbation; CCL, CC chemokine ligand; Cl, confidence interval; HR, hazard ratio; IL, interleukin; mMRC, modified Medical Research Council score for shortness of breathe; PDGF, platelet-derived growth factor.

volunteers were significantly different from IPF patients in this study. We cannot deny these differences affected the difference in serum cytokine levels between IPF patients and healthy volunteers; however, Drubaix reported agedependent decrease in production of PDGF and b-FGF (47). Higher serum levels of these cytokines in IPF patients did not depend on their older ages than healthy volunteers.

\section{Conclusions}

This study found that patient survival and AE of IPF could be predicted by the serum PDGF/\%FVC value. However, the prognostic importance of this parameter requires validation in further studies. In addition, whether serum levels of PDGF/\%FVC can predict the effects of nintedanib on IPF is important problem to be solved in the future studies.

\section{Acknowledgments}

We are grateful to Ms. Y Matsui for her secretarial work. Funding: This study was partially supported by a JSPS
KAKENHI grant (number JP17K09636) awarded to TA, YI, and MH, a National Hospital Organization grant (H28NHO [Kokyu]-2) awarded to TA and YI, and AMED grants (DLD/14526278 and PAP/14526182) awarded to YI and to YI and TA, respectively.

\section{Footnote}

Reporting Checklist: The authors have completed the STROBE reporting checklist. Available at https://jtd. amegroups.com/article/view/10.21037/jtd-21-1418/rc

Data Sharing Statement: Available at https://jtd.amegroups. com/article/view/10.21037/jtd-21-1418/dss

Peer Review File: Available at https://jtd.amegroups.com/ article/view/10.21037/jtd-21-1418/prf

Conflicts of Interest: All authors have completed the ICMJE uniform disclosure form (available at https://jtd.amegroups. com/article/view/10.21037/jtd-21-1418/coif). YI is members of steering committees or advisor of Boehringer 
Ingelheim, Taiho, Roche, GALAPAGOS and SAVARA (not related to this study). YI has received lecture fees from Boehringer Ingelheim, Kyorin, GSK and Shionogi (not related to this study). YI has received supports of medical writing from Boehringer Ingelheim about other manuscripts related to other clinical trial (not related to this study). TA has received lecture fees from Boehringer Ingelheim and Shionogi for activities not connected with the submitted work. MH reports a grant from Japanese Society for the Promotion of Science (JSPS), but has no competing interest. The other authors have no conflicts of interest to declare.

Ethical Statement: The authors are accountable for all aspects of the work in ensuring that questions related to the accuracy or integrity of any part of the work are appropriately investigated and resolved. The study was conducted in accordance with the Declaration of Helsinki (as revised in 2013). The study was approved by the National Hospital Organization Kinki-Chuo Chest Medical Center institutional review board (approval numbers 651 and 365) All study participants provided written informed consent for inclusion of their data in the study.

Open Access Statement: This is an Open Access article distributed in accordance with the Creative Commons Attribution-NonCommercial-NoDerivs 4.0 International License (CC BY-NC-ND 4.0), which permits the noncommercial replication and distribution of the article with the strict proviso that no changes or edits are made and the original work is properly cited (including links to both the formal publication through the relevant DOI and the license). See: https://creativecommons.org/licenses/by-nc-nd/4.0/.

\section{References}

1. King TE Jr, Pardo A, Selman M. Idiopathic pulmonary fibrosis. Lancet 2011;378:1949-61.

2. Raghu G, Collard HR, Egan JJ, et al. An official ATS/ ERS/JRS/ALAT statement: idiopathic pulmonary fibrosis: evidence-based guidelines for diagnosis and management. Am J Respir Crit Care Med 2011;183:788-824.

3. Raghu G, Remy-Jardin M, Myers JL, et al. Diagnosis of Idiopathic Pulmonary Fibrosis. An Official ATS/ERS/JRS/ ALAT Clinical Practice Guideline. Am J Respir Crit Care Med 2018;198:e44-68.

4. Collard HR, Ryerson CJ, Corte TJ, et al. Acute Exacerbation of Idiopathic Pulmonary Fibrosis. An
International Working Group Report. Am J Respir Crit Care Med 2016;194:265-75.

5. Kondoh Y, Taniguchi H, Kawabata Y, et al. Acute exacerbation in idiopathic pulmonary fibrosis. Analysis of clinical and pathologic findings in three cases. Chest 1993;103:1808-12.

6. Arai T, Kagawa T, Sasaki Y, et al. Heterogeneity of incidence and outcome of acute exacerbation in idiopathic interstitial pneumonia. Respirology 2016;21:1431-7.

7. Kondoh Y, Taniguchi H, Katsuta T, et al. Risk factors of acute exacerbation of idiopathic pulmonary fibrosis. Sarcoidosis Vasc Diffuse Lung Dis 2010;27:103-10.

8. Heukels P, Moor CC, von der Thüsen JH, et al. Inflammation and immunity in IPF pathogenesis and treatment. Respir Med 2019;147:79-91.

9. She YX, Yu QY, Tang XX. Role of interleukins in the pathogenesis of pulmonary fibrosis. Cell Death Discov 2021;7:52.

10. Inoue $Y$, Kaner RJ, Guiot J, et al. Diagnostic and Prognostic Biomarkers for Chronic Fibrosing Interstitial Lung Diseases With a Progressive Phenotype. Chest 2020;158:646-59.

11. Willems S, Verleden SE, Vanaudenaerde BM, et al. Multiplex protein profiling of bronchoalveolar lavage in idiopathic pulmonary fibrosis and hypersensitivity pneumonitis. Ann Thorac Med 2013;8:38-45.

12. Hilberg F, Roth GJ, Krssak M, et al. BIBF 1120: triple angiokinase inhibitor with sustained receptor blockade and good antitumor efficacy. Cancer Res 2008;68:4774-82.

13. Nishioka Y, Azuma M, Kishi M, et al. Targeting plateletderived growth factor as a therapeutic approach in pulmonary fibrosis. J Med Invest 2013;60:175-83.

14. Gharaee-Kermani M, Phan SH. Role of cytokines and cytokine therapy in wound healing and fibrotic diseases. Curr Pharm Des 2001;7:1083-103.

15. Guzy RD, Li L, Smith C, et al. Pulmonary fibrosis requires cell-autonomous mesenchymal fibroblast growth factor (FGF) signaling. J Biol Chem 2017;292:10364-78.

16. Guzy RD, Stoilov I, Elton TJ, et al. Fibroblast growth factor 2 is required for epithelial recovery, but not for pulmonary fibrosis, in response to bleomycin. Am J Respir Cell Mol Biol 2015;52:116-28.

17. Ando M, Miyazaki E, Ito T, et al. Significance of serum vascular endothelial growth factor level in patients with idiopathic pulmonary fibrosis. Lung 2010;188:247-52.

18. Yoshida M, Sakuma J, Hayashi S, et al. A histologically distinctive interstitial pneumonia induced by overexpression of the interleukin 6, transforming growth 
factor beta 1, or platelet-derived growth factor B gene. Proc Natl Acad Sci U S A 1995;92:9570-4.

19. Aono $Y$, Nishioka $Y$, Inayama M, et al. Imatinib as a novel antifibrotic agent in bleomycin-induced pulmonary fibrosis in mice. Am J Respir Crit Care Med 2005;171:1279-85.

20. Taniguchi H, Ebina M, Kondoh Y, et al. Pirfenidone in idiopathic pulmonary fibrosis. Eur Respir J 2010;35:821-9.

21. Arai T, Tachibana K, Sugimoto C, et al. High-dose prednisolone after intravenous methylprednisolone improves prognosis of acute exacerbation in idiopathic interstitial pneumonias. Respirology 2017;22:1363-70.

22. Arai T, Inoue Y, Tachibana K, et al. Cytomegalovirus infection during immunosuppressive therapy for diffuse parenchymal lung disease. Respirology 2013;18:117-24.

23. Celli BR, MacNee W; ATS/ERS Task Force. Standards for the diagnosis and treatment of patients with COPD: a summary of the ATS/ERS position paper. Eur Respir J 2004;23:932-46.

24. Arai T, Inoue Y, Sugimoto C, et al. CYFRA 21-1 as a disease severity marker for autoimmune pulmonary alveolar proteinosis. Respirology 2014;19:246-52 .

25. Ishikawa N, Hattori N, Yokoyama A, et al. Utility of KL-6/MUC1 in the clinical management of interstitial lung diseases. Respir Investig 2012;50:3-13.

26. Takahashi H, Shiratori M, Kanai A, et al. Monitoring markers of disease activity for interstitial lung diseases with serum surfactant proteins A and D. Respirology 2006;11 Suppl:S51-4.

27. Inoue $\mathrm{Y}$, Trapnell BC, Tazawa R, et al. Characteristics of a large cohort of patients with autoimmune pulmonary alveolar proteinosis in Japan. Am J Respir Crit Care Med 2008;177:752-62.

28. Richards TJ, Kaminski N, Baribaud F, et al. Peripheral blood proteins predict mortality in idiopathic pulmonary fibrosis. Am J Respir Crit Care Med 2012;185:67-76.

29. Tsoutsou PG, Gourgoulianis KI, Petinaki E, et al. Cytokine levels in the sera of patients with idiopathic pulmonary fibrosis. Respir Med 2006;100:938-45.

30. De Lauretis A, Sestini P, Pantelidis P, et al. Serum interleukin 6 is predictive of early functional decline and mortality in interstitial lung disease associated with systemic sclerosis. J Rheumatol 2013;40:435-46.

31. Prasse A, Probst C, Bargagli E, et al. Serum CCchemokine ligand 18 concentration predicts outcome in idiopathic pulmonary fibrosis. Am J Respir Crit Care Med 2009;179:717-23.

32. Rawlings SA, Heldt $S$, Prattes J, et al. Using Interleukin 6 and 8 in Blood and Bronchoalveolar Lavage Fluid to
Predict Survival in Hematological Malignancy Patients With Suspected Pulmonary Mold Infection. Front Immunol 2019;10:1798.

33. Shinoda H, Tasaka S, Fujishima S, et al. Elevated CC chemokine level in bronchoalveolar lavage fluid is predictive of a poor outcome of idiopathic pulmonary fibrosis. Respiration 2009;78:285-92.

34. Huang M, Sharma S, Zhu LX, et al. IL-7 inhibits fibroblast TGF-beta production and signaling in pulmonary fibrosis. J Clin Invest 2002;109:931-7.

35. van den Brûle S, Heymans J, Havaux X, et al. Profibrotic effect of IL-9 overexpression in a model of airway remodeling. Am J Respir Cell Mol Biol 2007;37:202-9.

36. Wilson MS, Madala SK, Ramalingam TR, et al. Bleomycin and IL-1beta-mediated pulmonary fibrosis is IL-17A dependent. J Exp Med 2010;207:535-52.

37. Puxeddu I, Bader R, Piliponsky AM, et al. The CC chemokine eotaxin/CCL11 has a selective profibrogenic effect on human lung fibroblasts. J Allergy Clin Immunol 2006;117:103-10.

38. Günther A, Korfei M, Mahavadi P, et al. Unravelling the progressive pathophysiology of idiopathic pulmonary fibrosis. Eur Respir Rev 2012;21:152-60.

39. Yoshida M, Sakuma-Mochizuki J, Abe K, et al. In vivo gene transfer of an extracellular domain of platelet-derived growth factor beta receptor by the HVJ-liposome method ameliorates bleomycin-induced pulmonary fibrosis. Biochem Biophys Res Commun 1999;265:503-8.

40. Antoniades HN, Bravo MA, Avila RE, et al. Plateletderived growth factor in idiopathic pulmonary fibrosis. J Clin Invest 1990;86:1055-64.

41. Homma S, Nagaoka I, Abe H, et al. Localization of platelet-derived growth factor and insulin-like growth factor I in the fibrotic lung. Am J Respir Crit Care Med 1995;152:2084-9.

42. Martinet Y, Rom WN, Grotendorst GR, et al. Exaggerated spontaneous release of platelet-derived growth factor by alveolar macrophages from patients with idiopathic pulmonary fibrosis. N Engl J Med 1987;317:202-9.

43. Oishi K, Mimura-Kimura Y, Miyasho T, et al. Association between cytokine removal by polymyxin B hemoperfusion and improved pulmonary oxygenation in patients with acute exacerbation of idiopathic pulmonary fibrosis. Cytokine 2013;61:84-9.

44. Hoffmann-Vold AM, Weigt SS, Saggar R, et al. Endotype-phenotyping may predict a treatment response in progressive fibrosing interstitial lung disease. EBioMedicine 2019;50:379-86. 
45. Zhu X, Fang X, Chen W, et al. Lower expression of platelet derived growth factor is associated with better overall survival rate of patients with idiopathic nonspecific interstitial pneumonia. J Thorac Dis 2017;9:519-28.

46. Wollin L, Maillet I, Quesniaux V, et al. Antifibrotic and anti-inflammatory activity of the tyrosine kinase inhibitor nintedanib in experimental models of lung fibrosis. J

Cite this article as: Arai T, Hirose M, Kagawa T, Hatsuda K, Inoue Y. Platelet-derived growth factor can predict survival and acute exacerbation in patients with idiopathic pulmonary fibrosis. J Thorac Dis 2022;14(2):278-294. doi: 10.21037/jtd-211418
Pharmacol Exp Ther 2014;349:209-20.

47. Drubaix I, Giakoumakis A, Robert L, et al. Preliminary data on the age-dependent decrease in basic fibroblast growth factor and platelet-derived growth factor in the human vein wall and in their influence on cell proliferation. Gerontology 1998;44:9-14. 